\title{
Micro-jet Pump for Micro-fluidic Systems
}

\author{
Xiuhan $\mathrm{Li}^{1}$, Xiaomei $\mathrm{Yu}^{1}$, Haihang $\mathrm{Cui}^{2}$, Zhanhua $\mathrm{Li}^{2}$, Dacheng Zhang ${ }^{1}$ \\ ${ }^{l}$ Institute of Microelectronics, Peking University, Beijing, 100871, China \\ ${ }^{2}$ Institute of Mechanics Chinese Academy Sciences, Beijing, 100080, China
}

\begin{abstract}
A novel micro-jet pump based on the principle of macroscopic jet pump are presented. The micro-jet pump can be used very easily for sampling in micro-fluidic systems under gas actuation. Vacuum suction mode provided by the pump can effectively decreases the formation of air bubbles and overcomes the interface tension between the liquid and solid wall in the micro-fluidic systems. Structurally the pump consists of a nozzle, a throat pipe and a pump chamber, which can be fabricated by means of silicon micro-machining technology. To obtain optimized parameters for the future designs, various pump configurations with different geometries were simulated through FLUENT, and the characteristics of the gas-actuated micro-jet pump was studied experimentally. The pump began to work at a threshold gas actuation pressure of $2 \mathrm{kPa}$, which can be realized easily by a medical syringe.
\end{abstract}

\section{Keywords-micro-jet pump; nozzle; diffuser; throat pipe}

\section{INTRODUCTION}

Recently micro-systems have been applied in extending fields of application. In many cases, peripheral components to support such systems are not available in an equivalently miniaturized form, which impedes the introduction of microsystems and extends volume and media consumption considerably. The increasing importance of micro-systems demands miniaturization of peripheral devices as well, this holds true, especially for analytical and biomedical applications, where micro pumps for fluids and gases are necessary[1]

Many design concepts and prototype of micro-pumps have been demonstrated over the past years. The proposed pumps require either mechanically moving parts or do not meet the requirements for high flow rate or low pressure. Moving parts, in most cases membranes fabricated of silicon or additionally required active or passive valves, may result in short lifetime and low reliability. Displacement pumps with bimetallic [2], electrostatic $[3,4]$, thermo-pneumatic [5,6], piezoelectric [7,8] and other drivers[9] have been reported. The properties of those systems regarding long term stability are still not known. Another kind of micro pumps i.e. dynamic pumps which include electro-hydrodynamic [10,11] electro-wetting[12,13] , electro-osmotic [14,15], and magneto hydro-dynamic [16,17] are widely used in micro fluidic systems. But they could not avoid of using complex additional driving equipment which increased the cost and decreased its widespread availability.

In order to avoid of the above shortcomings, a new type of micro-jet pump was put forward in this work. As we all known that vacuum suction mode provided by the pump can effectively decreases the formation of air bubbles and overcomes the interface tension between the liquid and solid wall in the micro-fluidic systems [18], hence gas pumping is a good method for microchip filling. The novel aspect of this work is to design a gas actuated micro-jet pump based on macroscopic jet theory, which can be fabricated easily with one mask process and integrated with most micro-fluidic systems. The advantages of this pump are giving as: no moving parts and valves; no friction and wear; scarcely have any backflow; easy and simple fabrication process; gas exhaust to atmospheric pressure should be possible; can be easily actuated by a syringe.

\section{THEORY AND SIMULATION}

Our approach is based on the idea of scaling down of wellknown macroscopic type pumps, these pumps are still widely used for vacuum generation in industry fields. In micro-jet pump (Fig.1), Elevated pressure of gas inside the jet assembly is converted to kinetic energy of a high velocity jet after it passes through a nozzle [1]. The pumping is achieved via momentum transfer in the jet direction. The continuous jet gas through the nozzle creates a net flow of gas in one direction, which provides a vacuum suction mode in microchip. It can be used for sampling in micro micro-fluidic systems. According to 2-D incompressible turbulent jet theory [19], the axial velocity $v_{m}$ of the jet and the throat velocity $v_{\mathrm{c}}$, which is indicated in Fig. 1, can be calculated from:

$$
\begin{gathered}
\frac{v_{m}}{v_{0}}=\left(\sqrt{\frac{2}{\pi}} \frac{1}{\varepsilon}\right)^{1 / 2}\left(\frac{2 b_{0}}{x}\right)^{1 / 2} \\
v_{c}=\frac{\sqrt{\pi} \varepsilon}{2} v_{m} .
\end{gathered}
$$

Where $b_{0}$ is the width of the nozzle, $x$ is the distance from nozzle to the jet plane center, $\mathcal{E}$ is 0.154 that was generalized from experimental results [19].

Under one of working conditions, there is a group of best structure parameters for the micro-jet pump. To acquire the key parameters for future designs, various pump configurations with different geometries were designed and simulated by $2 \mathrm{D}$ device simulator FLUENT. The optimized structure parameters for the micro-jet pump include the throat pipe length $\mathrm{d}$, which is the distance between the nozzle and the diffuser, the throat taper angle $\theta$ and the nozzle angle $\alpha$. According to our former experimental results, when the nozzle angle is $30^{\circ}$, the pump gains the best performance [20]. So the pumps with a fixed nozzle angle of $30^{\circ}$ were simulated and designed in this work.

Firstly we use gambit to model the micro-jet pump, the areas was meshed by sub-map or map with quad meshes. The boundary types set-up were shown in table I.

This work was supported by the National Natural Science Foundation of China (founded No. 90207013) and the National High Technology Research and Development Program of China (863 Program, project No. 2002AA 404420) 


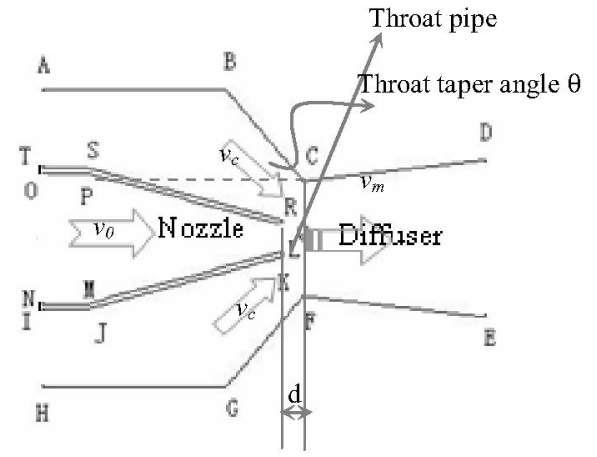

Figure 1. Planar schematics of a micro-jet pump (Here $\mathrm{AB}=700 \mu \mathrm{m}$; $\mathrm{AT}=100 \mu \mathrm{m} ; \mathrm{ON}=500 \mu \mathrm{m} ; \mathrm{QL}=100 \mu \mathrm{m}$, the width of the nozzle outlet $\mathrm{d}_{1}$ is $100 \mu \mathrm{m}, \mathrm{CF}=400 \mu \mathrm{m}$; the thickness of the nozzle wall is $20 \mu \mathrm{m}$, the nozzle angle is $30^{\circ}$.

TABLE I. BOUNDARY CONDITION TYPES FOR EACH EDGE STYLES

\begin{tabular}{|c|c|c|c|}
\hline Edge & ON & DE & AT \\
\hline Boundary type & Pressure inlet & Pressure outlet & Pressure inlet \\
\hline
\end{tabular}

2D FLUENT (K-epsilon) simulation tool was used to solve the influences of the two parameters on the suction pressure. The simulation results were shown in Fig. 2 and 3, which were done by optimizing one parameter while keep the other parameters fixed.

Firstly we changed the throat pipe length $\mathrm{d}$ from $80 \mu \mathrm{m}$ to $150 \mu \mathrm{m}$ and fixed the $2 \theta$ of $30^{\circ}$, the $\alpha$ of $50^{\circ}$. Figure 2 shows the simulation result for the mass flow rate of the throat pipe versus $\mathrm{d}$. The simulation results for the relationship between the secondary flow rate $v_{2}$ and the throat pipe length $\mathrm{d}$ was shown in Fig. 2. From this figure we could see that the mass flow rate changed with the throat pipe length $d$ and the maximum value of $v_{2}$ was gained when d equals to $115 \mu \mathrm{m}$.

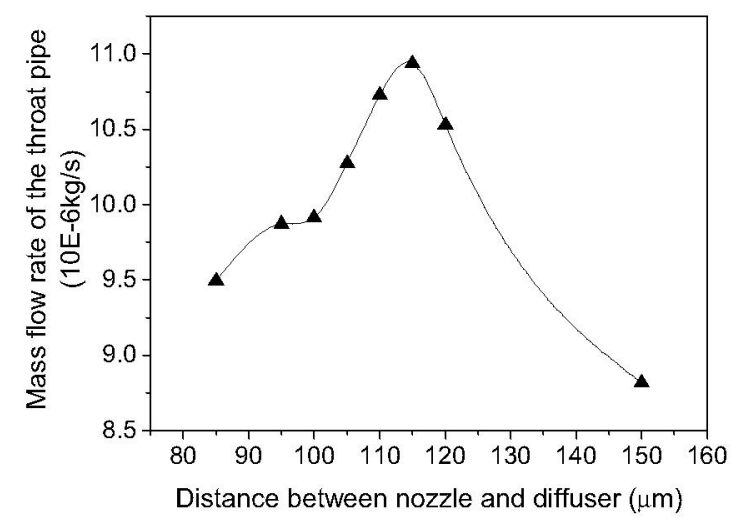

Figure 2. Relationship between the mass flow rate of throat pipe and the distance (d) between the nozzle and the diffuser, when $d=115 \mu \mathrm{m}$, the pump gains the best performance, under the driven pressure set to be $60 \mathrm{kPa}$.
Then we changed the throat taper angle $\theta$ in the range of $7.5-40^{\circ}$ and while fixed the other parameters, the simulation results were shown in Fig. 3. It is clear that the pump gain higher mass flow rate at a $\theta$ of $13^{\circ}$. Hence the best structure parameters were gained at the nozzle angle of $30^{\circ}$, the throat pipe length of $115 \mu \mathrm{m}$, and the taper angle $\theta$ of $13^{\circ}$.

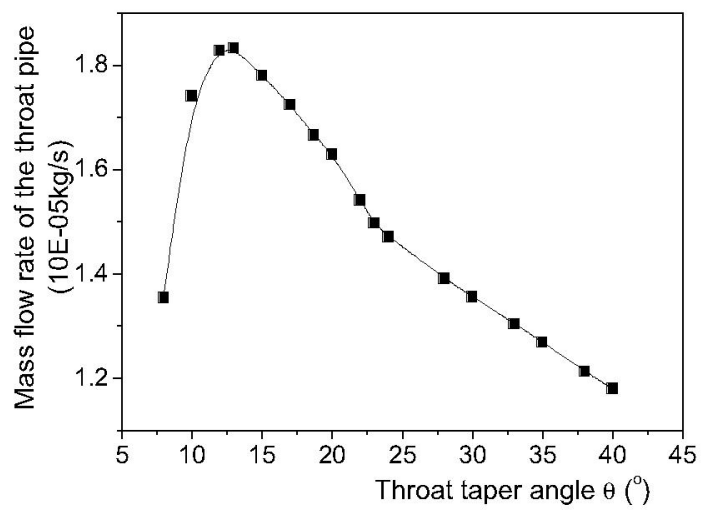

Figure 3. Relationship between mass flow rate of the throat pipe and the throat taper angle $\theta$, when $\theta=13^{\circ}$, the mass flow rate reaches the highest value, under the driven pressure set to be $60 \mathrm{kPa}$.

The main structure of the micro-jet pump was fabricated on a silicon substrate by deep reactive ion etching (DRIE). The flow ways were sealed by the anodic bonding of a Pyrex glass wafer. Another DRIE step was carried out from the backside of silicon wafer to form the outlet holes of fluid. Fig.4 is the SEM photo for the finished micro-jet pump which consists of the nozzle, the throat pipe; the suction tubes and the diffuser (refer to Fig.1). From Fig.4 we can see that the nozzle was connected with the actuation chamber, while the suction tubes were connected with the suction chamber. The width of the nozzle outlet is $100 \mu \mathrm{m}$, the width of the nozzle wall is $20 \mu \mathrm{m}$, and the depth of the micro-jet pump is $80 \mu \mathrm{m}$.

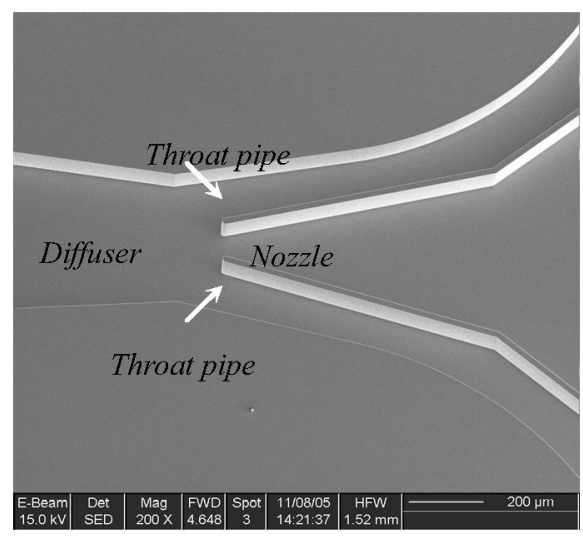

Figure 4. Relationship SEM image of a micro-jet pump fabricated through silicon micro-machining technology. 


\section{Measuremental Setup}

Stationary flow measurements were performed on the pump units using compressed nitrogen as the actuated fluid at a constant temperature. The schematic diagram of stationary flow measurement set-up was shown in Fig. 5. The actuation gas was connected to the fluid inlet port of the actuation chamber, the pressure value of which is measured by a commercial pressure transducer.

In order to measure the suction pressure of the pumps under different actuation pressures, a capillary tube with the inner diameter of $1 \mathrm{~mm}$ is vertically connected to the fluid inlet ports of suction chamber, the other end of which is immersed into the water. The suction pressure, indicated by the increase of the water column height in the capillary tube, was measured through a square caliper. The pump in our experiment has been measured at least three times.

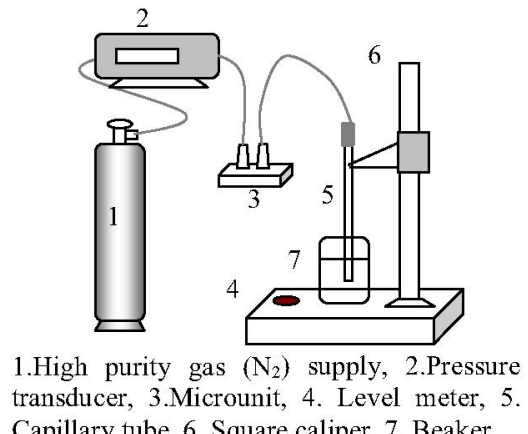

Figure 5. Schematic of stationary flow measurement set-up, pure gas $\left(\mathrm{N}_{2}\right)$ was connected with the driven gas inlet port, the pressure of which is measured by a commercial pressure transducer, while the other port connect with a capillary tube. The height of the water column was surveyed by a square caliper.

\section{RESUlts AND Discussions}

The suction pressures in the suction chamber, indicated by the increase of the water column height in the capillary tube, as a function of the driven pressures for the micro-jet pump with the optimum structure parameters are shown in Fig. 6. The pump characteristics have been measured for three times, and the consecutive curve in Fig. 6 is the average result.

We can see from Fig. 6 that the micro-jet pump began to work at very low pressure (around $2 \mathrm{kPa}$ ), when the driven pressure below $42 \mathrm{kPa}$, the suction pressure changed very smoothly in a very small range, but over $42 \mathrm{kPa}$, the suction pressure increases greatly. When the driven pressure was over $50 \mathrm{kPa}$, the water column in the capillary tube was too high to be measured. The pump scarcely has any back flow before it works. Therefore the pump can be integrated with most bio micro-fluidic systems and especially in our future micro-fluidic PCR systems [21].

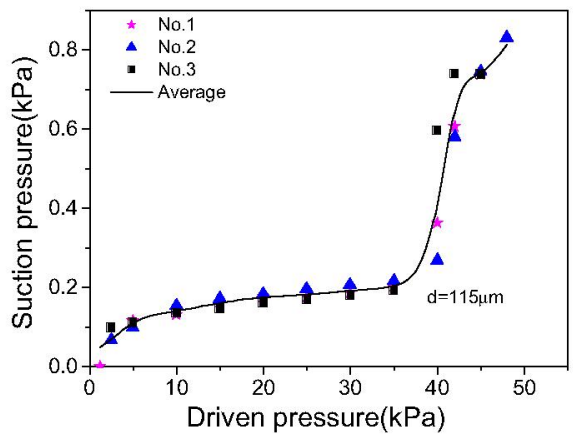

Figure 6. Suction pressure in the suction chamber as a function with the driven pressure in the driven chamber at $\mathrm{d}=115 \mu \mathrm{m}$. Nozzle width: $100 \mu \mathrm{m}$, nozzle angle $30^{\circ}$.

\section{CONCULSIONS}

A micro-jet pump is presented to meet the needs for a reliable micro vacuum pump based on the two dimensional jet theory and FLUENT simulation. The optimized pump performance was gained with the help of simulation tools, the best pump performance was gained at the $\mathrm{d}$ of $115 \mu \mathrm{m}$, the $\alpha$ of $13^{\circ}$ and the $\theta$ of $30^{\circ}$. To demonstrate the basic function, externally nitrogen gas was used to generate a gas jet, an experiment setup was designed to measure the pump performance. The pump began to work when the driven pressure was set to be $2 \mathrm{kPa}$ and the suction pressure increase quickly at a driven pressure of $42 \mathrm{kPa}$. The pump scarcely has any back flow before it works. Therefore the micro-jet pump appears to be a promising device in micro fluidic systems.

\section{REFERENCES}

[1] M. Doms and J. Mueller, "A micromachined vapor jet pump", Sensors and Actuators, vol.A119, pp. $462-467,2005$.

[2] H. Jerman, "Electrically activated, normally-closed diaphragm valves", J. Micromech. Microeng., vol.4, pp. 210-215, 1994.

[3] K. Sato and M. Shikida, "An electrostatically actuated gas valve with an S-shaped film element”, J. Micromech. Microeng. vol.4 pp.205-209, 1994.

[4] L. Yobas, M. A. Huff, F. J. Lisy and D. M. Durand, "A novel bulkmicromachined electrostatic microvalve with a curved-compliant structure applicable for a pneumatic tactile display ", J. Microelectromech. Syst., vol.10, pp. 187-196, 2001.

[5] C. Goll et al, "Microvalves with bistable buckled polymer diaphragms", J. Micromech. Microeng., vol 6 pp. 77-79,1996.

[6] W. K. Schomburg and C. Goll, "Design optimization of bistable microdiaphragm valves", Sensors and Actuators, vol.A64, pp. 259-264, 1998

[7] I. Chakraborty, W. C. Tang, D. P. Bame and T. K. Tang, "MEMS microvalve for space applications", Sensors and Actuators volA83, pp. 188$193,2000$.

[8] P. K. Yuen, L. J. Kricka and P. Wilding, "Semi-disposable microvalves for use with microfabricated devices or microchips", J. Micromech. Microeng.,vol.10, pp. 401-409, 2000.

[9] D. J. Laser, and J. G. Santiago, "A review of micropumps", J. Micromech. Microeng., vol.14, pp.35-64, 2004.

[10] S. H. Ahn and Y. K. Kim, "Fabrication and experiment of a planar micro ion drag pump", Sensors Actuators, vol.A70, pp. 1-5,1998. 
[11] J. Lee and C. J. Kim, "Surface-tension-driven microactuation based on continuous electrowetting", J. Microelectromech. Syst., vol.9, pp. 171$180,2000$.

[12] J. Lee, H. Moon, J. Fowler, T. Schoellhammer and C. J. Kim, "Electrowetting and electrowetting-on-dielectric for microscale liquid handling", Sensors Actuators, vol.A95, pp. 259-268, 2002.

[13] T. E. McKnight, C. T. Culbertson, S. C. Jacobson and J. M. Ramsey, "Electroosmotically induced hydraulic pumping with integrated electrodes in microfluidic devices", Anal. Chem., vol.73 pp. 4045-4049, 2001.

[14] S. L. Zeng, C. H. Chen, J. C. Mikkelsen and J. G. Santiago, "Fabrication and characterization of electroosmotic micropumps", Sensors Actuators, vol.B79, pp. 107-114, 2001.

[15] J. Darabi, M. Rada, M. Ohadi and J. Lawler, "Design, fabrication and testing of an electrohydrodynamic ion-drag micropump", J. Microelectromech. Syst., vol.11, pp. 684-690, 2002.
[16] J. S. Jang and S. S. Lee, "Theoretical and experimental study of MHD (magnetohydrodynamic) micropump", Sensors Actuators, vol.A80, pp. 84-89, 2000

[17] A. V. Lemoff and A. P. Lee, "An AC magnetohydrodynamic micropump", Sensors Actuators, vol.B63, pp.178-185, 2000.

[18] M. Jennifer, A. G. Andrew, and G. N. Ralph, "A method for filling complex polymeric microfluidic devices and arrays", Anal. Chem., vol. 73 , pp. 3193, 2001.

[19] Yu C. Z , "Turbulent Jet", Higher Education Press, pp. 24,1993.

[20] Li Xiu-Han et al., "Gas actuated micro-jet pump for micro-fluidic systems”, Micro TAS'05 Boston, MA USA, 2005

[21] Xiaomei Yu et al., "3-D microarrays biochip for DNA amplification in polydimethylsiloxane (PDMS) elastomer", Sensors and Actuators, vol.A.108, pp.103-107, 2003. 